\title{
COMPORTAMENTO DE MOTORISTAS COM SEMÁFOROS TEMPORIZADOS: UM ESTUDO UTILIZANDO ANÁLISE DE CORRESPONDÊNCIA
}

\author{
Behavior of drivers with timed semaphores: a study using \\ correspondence analysis
}

\author{
Annanda Hellen Gomes da Costa ${ }^{1}$, José Gilberto Spasiani Rinaldi ${ }^{2}$ \\ ${ }^{1}$ Universidade Estadual Paulista "Júlio de Mesquita Filho" \\ Faculdade de Ciências e Tecnologia, Graduação em Estatística \\ E-mail: annandacosta@hotmail.com \\ 2 Universidade Estadual Paulista "Júlio de Mesquita Filho" \\ Faculdade de Ciências e Tecnologia, Departamento de Estatística \\ E-mail: gilberto.rinaldi@unesp.br
}

RESUMO - Atualmente há um aumento significativo no número de veículos que transitam nas cidades brasileiras. Os agentes responsáveis pelo planejamento de fluxo de veículos têm utilizado de tecnologias para o enfrentamento dos problemas decorrentes deste fato com o objetivo principal de segurança no trânsito. Este trabalho trata de estudar o comportamento de risco dos motoristas diante de dois tipos de semáforos de trânsito, com e sem temporizador. Para este objetivo foi utilizada uma técnica de estatística multivariada denominada Análise de Correspondência sendo que esta relaciona as categorias de duas ou mais variáveis permitindo interpretações para classificar os motoristas segundo seu comportamento. Foram realizadas coletas amostrais na cidade de Presidente Prudente revelando que os motoristas têm um comportamento de se arriscarem mais com os semáforos sem temporizador. Uma das conclusões do estudo, talvez a mais importante, é devida ao fato de que os investimentos que foram realizados nos semáforos com temporizador podem ser considerados justificados considerando-se a diminuição de riscos de acidente.

Palavras-chave: comportamento no trânsito; análise de correspondência; risco de acidente.

ABSTRACT - Currently there is a significant increase in the number of vehicles that transit in Brazilian cities. The agents responsible for planning the flow of vehicles have used technologies to deal with the problems arising from this fact with the main objective of traffic safety. This paper tries to study the risk behavior of drivers in front of two types of traffic lights, with and without timer. For this purpose, a multivariate statistical technique called Correspondence Analysis was used, which correlates the categories of two or more variables allowing interpretations to classify drivers according to their behavior. Sample collections were carried out in the city of Presidente Prudente, revealing that drivers have a way of risking themselves more often with the traffic lights without a timer. One of the conclusions of the study,

Recebido em: $27 / 05 / 2018$ Revisado em: 23/08/2018 Aprovado em:30/08/2018 perhaps the most important one, is due to the fact that the investments that were made in the traffic lights with a timer can be considered justified considering the reduction of accident risks.

Keywords: behavior in traffic; correspondence analysis; accident risks. 


\section{INTRODUÇÃO}

Quando se trata de comportamento no trânsito, muitas características podem ser apontadas, como velocidade a que o motorista está trafegando, se há alguma negligência ao dirigir, como exemplos mais comuns, trafegar em vias não permitidas, avançar o cruzamento no sinal vermelho, não respeitar as faixas de pedestres, entre outros. Entretanto, encontrar maneiras de prevenir acidentes e manter o trânsito adequado, organizado e seguro com um fluxo de veículos crescente nas cidades é um desafio cuja solução não é tão simples.

Atualmente já existem novos meios tecnológicos que prometem trazer benefícios para a comunidade. Diferente dos mais comumente utilizados, que são as multas, estes auxiliam o condutor no momento de tomar algumas decisões no trânsito, porém o investimento para obter tal modernização é alto, e, nem toda cidade tem condições de arcar com os custos dessa tecnologia. Contudo, quando há o investimento, são poucos os estudos que avaliam se a mudança trouxe os benefícios esperados. Este conhecimento levanta a questão da conhecida relação entre custo e benefício, uma vez que as estatísticas apontem que tenha existido um benefício significativo o investimento é justificado como válido à sociedade que o financiou.

Este estudo, aqui apresentado, tem como principal objetivo avaliar a real eficiência das implantações de semáforos com temporizadores visíveis em Presidente Prudente. Foram analisados, por meio da técnica estatística multivariada denominada Análise de Correspondência, os comportamentos dos motoristas em relação aos dois tipos de semáforos, temporizados e não temporizados, sendo que estes coexistem nas principais vias da cidade.

Há pouquíssimos estudos sobre o comportamento de risco. Em Fortaleza (CE), os temporizadores não contribuíram para redução de acidentes e geraram dúvidas de interpretação entre os motoristas (FIGUEIRA,
2012). Outros trabalhos utilizam distribuições de probabilidade para dimensionar o tempo de abertura de um semáforo (VILLALOBOS, 2010).

Comumente, o que é encontrado na literatura a respeito de trânsito e semáforos traz contribuições a respeito do tempo a ser utilizado na temporização dos mesmos. A preocupação predominante é em relação à qualidade do fluxo, é de que este esteja adequado à quantidade de veículos que possa estar passando pela via estudada. Evidentemente esta é uma preocupação válida, contudo acidentes podem interferir de forma determinante no fluxo e na sua qualidade. É notório que, em cidades de médio e grande porte, quando um acidente ocorre, o fluxo de veículos pode ficar em estado caótico trazendo uma série de prejuízos aos usuários, atrasos de coletivos em seus horários, irritação por parte dos motoristas e, possivelmente, mais acidentes relacionados a esses inconvenientes citados. Deste modo, levantar possibilidades que diminuam os riscos de acidente que contribuem significativamente para a melhoria do fluxo por meio de técnicas de estatística adequadas pode auxiliar em levantar subsídios para isto, como é o caso deste estudo.

\section{METODOLOGIA}

Segundo a Legislação Brasileira existem quatro níveis de infração no trânsito, sendo elas classificadas como leves, médias, graves e gravíssimas, ou seja, as mesmas são relacionadas à gravidade do ocorrido. Para cada uma delas uma multa e uma quantia em pontos é cobrada do infrator, e, em alguns casos, medidas administrativas são tomadas, por exemplo, a suspensão do direito de dirigir, apreensão do veículo envolvido, entre outras.

Considerando isso, vê - se que é de extrema importância analisar e utilizar outros tipos de abordagem que exerçam esses papéis. Intervenções como palestras em escolas e propagandas são algumas das 
opções, bem como tecnologias que podem ser implantadas no trânsito que auxiliam na prevenção de práticas de risco.

Para esse estudo é relevante ressaltar que dentro dessa esfera, como infrações de nível gravíssimo consta o ato de avançar no sinal vermelho do semáforo. Aqui, pretende-se avaliar a frequência dessa ocorrência em duas situações distintas (dois tipos de semáforos). Esta é uma das atitudes por parte dos condutores de automóveis que podem colocar em risco a vida de pedestres e motoristas, devido a isto é classificada com o maior nível de periculosidade dentre os estabelecidos por lei.

Sabe-se atualmente que, para a cidade de Presidente Prudente - SP, foi identificado um crescimento na frota de autos muito similar ao que ocorre em todo o estado de São Paulo. Em fevereiro de 2016 a quantidade dessa categoria, incluindo automóveis, caminhões e ônibus, era de 157.892, ao passo que em 2017 houve um aumento de $2,9 \%$ no mesmo período, indo para 162.596 .

Este aumento foi proporcionalmente maior do que o crescimento populacional na mesma época. Segundo o IBGE (Instituto Brasileiro de Geografia e Estatística), a população de Presidente Prudente subiu de 223.749 em 2016 para 225.271 em 2017. Deste modo, um aumento de 0,68\%.

Essa tendência de crescimento é um reflexo da mudança no perfil dos cidadãos de Prudente e de todo Brasil. Nota-se que há, de modo geral, uma insatisfação com o transporte público, logo, cada vez mais pessoas migram para o privado. Além disso, as famílias que tem condições e necessidades relativas têm mostrado a tendência de possuir e utilizar mais de um veículo (carros e motos, entre outros) para se locomover.

Visto que a previsão para a frota de veículos segue uma tendência ao crescimento, espera-se com isso que o número de acidentes também aumente fazendo com que a qualidade e o fluxo do trânsito diminuam. Contudo, percebe-se que não basta apenas o método punitivo para reverter esse quadro. Atualmente já existem tecnologias voltadas para auxiliar o condutor e promover a prevenção da infração.

Uma dessas modernizações, que é utilizada como parte do estudo aqui apresentado, é o temporizador visível de semáforos. Este permite que o motorista visualize o tempo regressivo do sinal de verde, ou seja, quantos segundos ele possui para efetuar a travessia antes da ocorrência do sinal de amarelo. Isso viabiliza um maior poder de previsibilidade em conseguir ou não atravessar o cruzamento sem cometer uma infração.

\subsection{A coleta de dados}

Esse estudo teve como principal objetivo observar alguns comportamentos nos segundos finais de verde, de maneira que, ao compará-los nos semáforos com e sem temporizador visível, chegue-se à conclusão se houve melhorias com as novas aquisições tecnológicas da cidade.

Os dados foram coletados em quatro pontos semafóricos com fluxos independentes, sendo dois destes com temporizador e dois sem temporizador. Os locais escolhidos ficam em grandes avenidas na área central da cidade de Presidente Prudente. Para cada ponto foram feitas duas coletas em horários e dias da semana diferentes, para obter uma maior diversidade de fluxo de veículos, totalizando oito coletas.

Estas quatro grandes avenidas circundam uma área de vinte e cinco quarteirões denominada "quadrilátero central". Nesta área (vide Figura 1), em sua parte interna, há grande concentração de lojas comerciais, agências bancárias diversas, estacionamentos particulares (originados devido à falta de vagas nas ruas) e alguns edifícios mistos (comerciais e residenciais). 
Figura 1. Quadrilátero central de Presidente Prudente. Os pontos de coleta estão em amarelo.

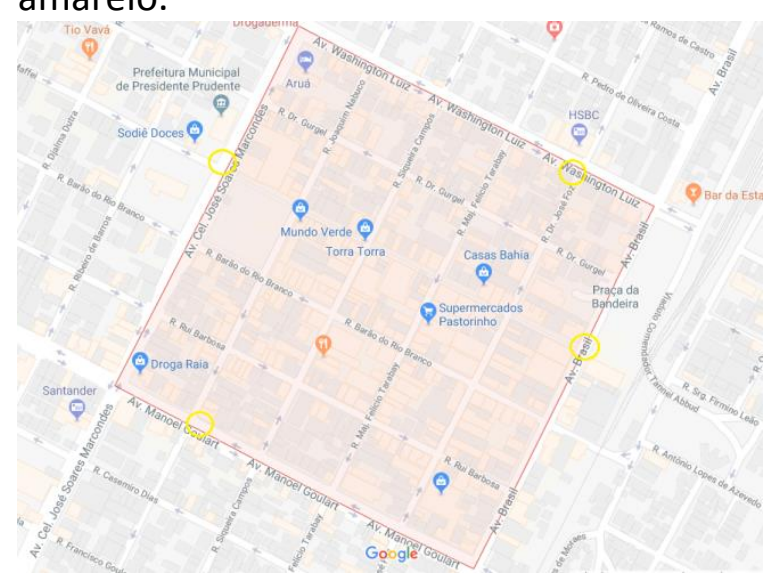

Fonte: Google Maps.

As grandes avenidas circundantes àquela área são responsáveis por todo o fluxo de veículos que entram e saem da mesma, assim sendo, assumem grande importância em relação à qualidade do trânsito de toda a região central e comercial da cidade.

Para que a coleta fosse devidamente realizada, foram avaliados quais tipos de comportamento poderiam ser observados para uma conclusão estatística confiável a respeito da conduta dos motoristas diante da decisão a ser tomada nos semáforos. Chegou-se à conclusão de que seriam necessárias duas variáveis categóricas, com três categorias cada.

\section{Variável 1: Corte}

- CA (Corte no Amarelo): Se durante o tempo de amarelo o veículo estiver no cruzamento considera-se corte no amarelo.

- CV (Corte no Vermelho): Se durante o tempo de vermelho o veículo estiver no cruzamento haverá corte no vermelho.

- SC (Sem Corte): Quando o motorista passa pelo cruzamento antes de ocorrer o sinal amarelo.

\section{Variável 2: Aceleração}

- Red: Representa o motorista que, ao se deparar com os segundos finais de verde, decide reduzir o veículo.

- Ac: Representa os motoristas que aceleraram nos segundos finais de verde.

- SA: Diz respeito àqueles que mantiveram a velocidade nos últimos segundos de verde (sem aceleração ou redução).

Para avaliar todas essas informações utilizando a Análise de Correspondência, e considerando que a intenção do trabalho é comparar os semáforos com e sem temporizador, deve-se dividir as oito amostras coletadas em dois grupos. Ou seja, as primeiras quatro amostras coletadas (com temporizador) em um grupo, e as demais em outro. A junção em dois grupos também ajuda a técnica em poder discriminar o comportamento dos motoristas de forma mais geral, isto pode uniformizar melhor o comportamento e concentrar as informações em situações mais representativas. Dessa forma, é possível comparar as duas situações através das tabelas de contingência e dos gráficos resultantes da análise de uma forma mais clara e objetiva.

Sendo definidas as variáveis e suas categorias, são então realizados os cruzamentos entre essas duas variáveis categóricas.

\subsection{A Análise de Correspondência}

Um teste Qui-Quadrado seria uma tentativa para avaliar uma associação global entre as variáveis estudadas, contudo, as suposições para esse teste são satisfeitas. A metodologia mais adequada para esta situação é uma técnica de Análise Estatística Multivariada, conhecida como Análise de Correspondência. Por meio desta técnica, é obtido como resultado um gráfico que irá apresentar dois grupos de pontos: o conjunto de I pontos que representam as linhas e o de $J$ pontos associados às colunas. Este gráfico é um biplano denominado frequentemente como mapa de percepções. Através dele é possível avaliar as associações entre as variáveis categóricas com base na posição 
desses grupos, ou seja, se os pontos de $I$ estão dispostos de forma associada aos pontos de J. Isso significa que os mesmos representam combinações com maior frequência entre as variáveis, ao contrário do que ocorre em um modelo de independência (no qual não haveria associação).

Aqui são suprimidos os cálculos para a obtenção dessas análises, maiores detalhes podem ser encontrados em literatura especializada (HAIR et al., 2005; AAKER, KUMAR; DAY, 2004; JOHNSON; WICHERN, 2002). A principal medida desse tipo de análise é a denominada inércia, esta representa a quantidade de toda a informação das variáveis estão contidas no biplano (o máximo é de 100\%). Esta pode ser considerada aceitável quando ultrapassa $70 \%$, contudo, quanto maior mais significativo é o resultado obtido.

\section{RESULTADOS}

O cruzamento da variável Corte e da variável da Aceleração está dividido em dois casos, semáforos com temporizador visível e sem temporizador. As tabelas 1 e 2 seguintes representam esses cruzamentos.

Ao comparar as tabelas, nota-se que a sem temporizador tem um índice ligeiramente maior do que a com temporizador quando se trata de corte no amarelo e vermelho. Prova disso é que na tabela 1 é obtido que 30,47\% não cortaram enquanto que na tabela 2 apenas 13,9\% agiram da mesma forma.

No entanto, percebe-se também que com respeito à variável Aceleração, quando há temporizador, houve mais casos onde o motorista acelerou $(53,12 \%)$ do que quando não há temporização no semáforo envolvido $(16,95 \%)$.
Tabela 1. Tabela de contingência das amostras referentes ao semáforo com temporizador.

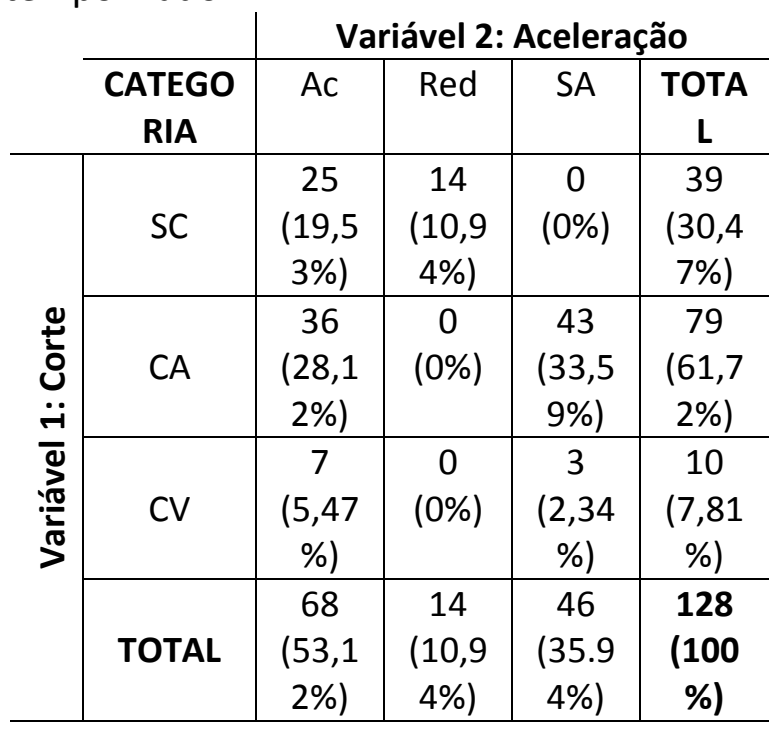

Fonte: Autoria própria.

Tabela 2. Tabela de contingência das amostras referentes ao semáforo sem temporizador.

\begin{tabular}{|c|c|c|c|c|c|}
\hline \multirow{2}{*}{\multicolumn{2}{|c|}{$\begin{array}{c}\text { CATEGO } \\
\text { RIA }\end{array}$}} & \multicolumn{4}{|c|}{ Variável 2: Aceleração } \\
\hline & & Ac & Red & SA & $\begin{array}{c}\text { TO } \\
\text { TAL }\end{array}$ \\
\hline \multirow{4}{*}{ 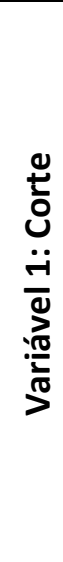 } & SC & $\begin{array}{c}8 \\
(2,71 \\
\%) \\
\end{array}$ & $\begin{array}{c}33 \\
(11,1 \\
9 \%) \\
\end{array}$ & $\begin{array}{c}0 \\
(0 \%)\end{array}$ & $\begin{array}{c}41 \\
(13,9 \\
\%) \\
\end{array}$ \\
\hline & CA & $\begin{array}{c}20 \\
(6,78 \\
\%) \\
\end{array}$ & $\begin{array}{c}0 \\
(0 \%)\end{array}$ & $\begin{array}{c}139 \\
(47,1 \\
2 \%) \\
\end{array}$ & $\begin{array}{c}159 \\
(53,9 \\
\%) \\
\end{array}$ \\
\hline & CV & $\begin{array}{c}22 \\
(7,46 \\
\%) \\
\end{array}$ & $\begin{array}{c}0 \\
(0 \%)\end{array}$ & $\begin{array}{c}73 \\
(24,7 \\
4 \%)\end{array}$ & $\begin{array}{c}95 \\
(32,2 \\
\%)\end{array}$ \\
\hline & TOTAL & $\begin{array}{c}50 \\
(16,9 \\
5 \%) \\
\end{array}$ & $\begin{array}{c}33 \\
(11,1 \\
9 \%)\end{array}$ & $\begin{array}{c}212 \\
(71,8 \\
6 \%) \\
\end{array}$ & $\begin{array}{c}295 \\
(100 \\
\%)\end{array}$ \\
\hline
\end{tabular}

Fonte: Autoria própria.

Primeiramente foi realizado o cruzamento das variáveis, como mencionado anteriormente, para uma primeira análise geral dos dados, de todos os dias de coleta. Com isso, visto que seria possível a aplicação da análise de correspondência simples para melhor análise dos dados, foram obtidos os resultados abaixo, vide Figuras 2 e 3, a seguir. 
Figura 2. Análise de Correspondência das coletas com temporizador.

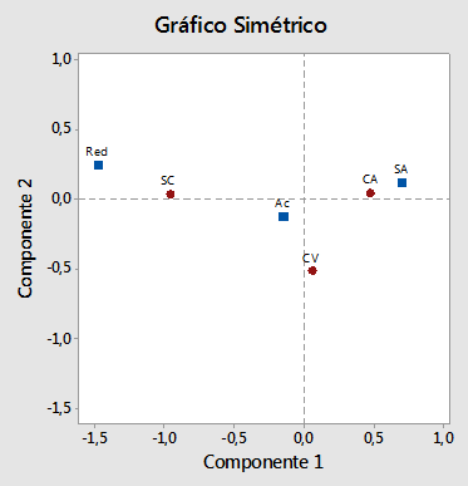

Fonte: Autoria própria.

Figura 3. Análise de correspondência das coletas sem temporizador.

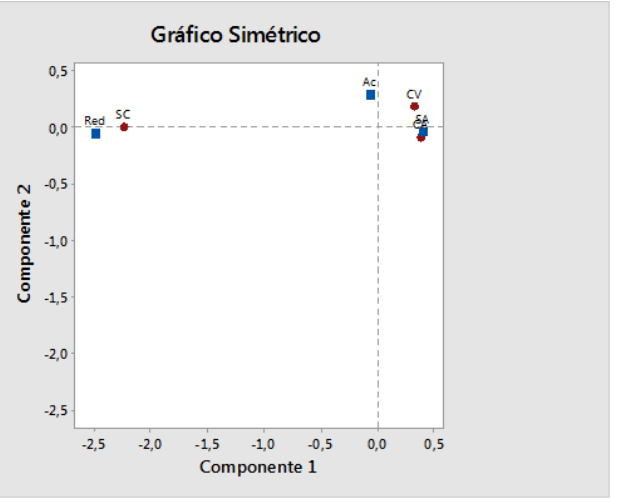

Fonte: Autoria própria.

Pelos biplanos pode-se observar que as disposições entre as categorias estão bem diferentes para as análises de correspondência das coletas sem temporizador e com temporizador. Isto, inicialmente, revela que os comportamentos dos motoristas são diferentes, ou seja, de alguma forma, os motoristas tem comportamentos diferentes se comparadas essas duas situações. Deve-se observar que os valores de inércia para os dois biplanos estão superiores a $70 \%$, logo são representativos e suas análises podem ser consideradas válidas.

\section{DISCUSSÃO}

Pode-se observar através da Figura 2 que a categoria "SC" (Sem corte) está consideravelmente associada à categoria "Red", o que é esperado, já que se o motorista reduziu dificilmente o mesmo vai cortar o sinal de amarelo ou vermelho.

Outras categorias também possuem associações interessantes, exemplo disso são as categorias "Ac" (Acelerou) com a "CV" (Corte no vermelho), e a "SA" (Sem ação, sem aceleração ou redução da velocidade) com a "CA" (Corte no amarelo). As duas primeiras parecem mais associadas entre elas e o mesmo ocorre entre as duas últimas citadas. No caso em que há temporização, o motorista se depara com o fim do tempo de verde e, com isso, ao perceber que tem tempo suficiente para cruzar a via mantém a velocidade. Como resultado disso, parte desses motoristas acaba cortando o sinal de amarelo sem acelerar o veículo.

Considerando que o motorista visualizou o temporizador, e percebeu que não há tempo para atravessar a via, poucos optaram por reduzir, os demais aceleraram e, dentre eles, poucos não cortaram os sinais, os demais cortaram os sinais amarelo e vermelho, este último mais frequentemente em situações em que o motorista acelerou o veículo.

Logo, concluí-se que, com o aparelho mostrando o tempo restante de verde, há uma melhora quanto à proporção de cortes, porém o aparelho se torna um motivo a mais para comportamentos como acelerar o veículo na tentativa de passar pelo semáforo antes de ocorrer o sinal vermelho.

Analisando-se a Figura 3, percebe-se por meio do biplano, que existe forte associação da categoria "Red" (Reduzir) com a "SC", da mesma forma isso ocorre na Figura 1. Se o motorista reduziu muito provavelmente ele não cortará os sinais amarelo e vermelho.

Além disso, nota - se que tanto a categoria "CV" (Corte no vermelho) quanto a "CA" (Corte no amarelo) está mais associada à "SA" (Sem ação, quando não acelera e nem reduz) do que "Ac" (Acelerar). Considerando que, neste caso se trata de semáforos sem temporizador, essa é uma informação relevante. Isso mostra que quando o motorista não tem o poder de antecipar o tempo de verde que ainda lhe sobra, a 
tendência é que o mesmo não acelere o veículo. No entanto, ainda assim há mais cortes do que com temporizador, pois, o tempo de reação do motorista ao se deparar com o sinal de amarelo leva-o a fazer o corte e, em muitas vezes, agir por impulso e cortar o sinal vermelho.

\section{CONCLUSÃO}

Analisando-se os biplanos obtidos, está claro que de fato o temporizador trouxe benefícios para sociedade, através da redução da proporção de cortes, porém, também causa alguns comportamentos indesejados, como o aumento da ocorrência de aceleração do veículo, já mencionada anteriormente.

Deve-se trabalhar com a implantação de mais semáforos com temporizador aliada à educação no trânsito com o objetivo de levar o motorista a ter mais reflexão na decisão relacionada ao temporizador. A combinação desses fatores parece ser uma estratégia interessante a ser cultivada.

\section{REFERÊNCIAS}

AAKER, D.A.; KUMAR, V.; DAY, G.S. Pesquisa de marketing. 2. ed. São Paulo: Atlas, 2004.

FIGUEIRA, T. S. A influência da temporização semafórica no comportamento dos motoristas. 2012. 89f. Dissertação (Mestrado) Universidade Federal do Rio de Janeiro, Rio de Janeiro, 2012.

HAIR, J. F. et al. Análise multivariada de dados. 5. ed. Porto Alegre: Bookman, 2005.

JOHNSON, R.A.; WICHERN, D.W. Applied multivariate statistical analysis. 5. ed. New Jersey: Pratice Hall, 2002.

VILLALOBOS, L. D. C. Uso da distribuição probabilística dos fluxos veiculares no cálculo da programação de um semáforo a tempo fixo modo isolado. In: Encontro Nacional de Engenharia de Produção, 30., 2010. Anais... São Carlos: UFSCar, 2010. 